\title{
The Growth Inhibitory Activity of Tasmannia lanceolata (Poir.) A.C. Sm against the Food-poisoning Pathogen Yersinia enterocolitica
}

\author{
Huda Aldosary' Mitchell Henry Wright ${ }^{2, *}$, Cameron Jay Lee ${ }^{1}$, Anthony Carlson Greene ${ }^{1}$, Ian Edwin Cock ${ }^{1,3, *}$ \\ 'School of Environment and Science, Griffith University, Brisbane, Queensland, AUSTRALIA. \\ 2Department of Research and Development, First Choice College, Gold Coast, Queensland, AUSTRALIA. \\ 'Environmental Futures Research Institute, Griffith University, Brisbane, Queensland, AUSTRALIA
}

\begin{abstract}
Introduction: Yersinia enterocolitica is a major source of food poisoning via the consumption of contaminated meat products, causing acute gastroenteric yersiniosis. Tasmannia lanceolata has been widely documented for its antiseptic properties, repressing the growth of an extensive range of bacteria. Despite this, Tasmannia lanceolata has yet to be been tested for its inhibitory capacity against Y. enterocolitica. Methods: T. lanceolata leaf and berry extracts were prepared by maceration and growth inhibitory activity against a clinical strain of $Y$. enterocolitica was examined by disc diffusion assays. The MIC values of the extracts were determined to quantify and compare their relative efficacies. Toxicity was determined using an Artemia franciscana nauplii bioassay. Results: T. lanceolata leaf and berry extracts displayed potent growth inhibitory activity in the disc diffusion assay against $Y$. enterocolitica. The ethyl acetate and chloroform leaf extracts (MICs of 30 and $53 \mu \mathrm{g} / \mathrm{mL}$ respectively) and the hexane berry extract (MIC $=34 \mu \mathrm{g} / \mathrm{mL}$ ) were particularly potent growth inhibitors. The methanol and water extracts of both the berry and leaf, as well as the leaf ethyl acetate extract, also had strong growth inhibitory activity against $Y$. enterocolitica, albeit with a higher MIC values $(250-300 \mu \mathrm{g} / \mathrm{mL})$. All other extracts had lower efficacy, although their MIC values also indicated good inhibitory activity (with the exception of the chloroform berry extract). When assessed for toxicity, all $T$. lanceolata extracts were non-toxic $\left(\mathrm{LC}_{50}\right.$ values $>1000 \mu \mathrm{g} / \mathrm{mL}$ )
\end{abstract}

in the Artemia franciscana bioassay. Conclusion: The non-toxicity of the T. lanceolata berry and leaf extracts, combined with the potent inhibitory bioactivity observed against $Y$. enterocolitica, demonstrates their potential as therapeutic agents in the prevention and treatment of yersiniosis.

Key words: Yersinia enterocolitica, Yersiniosis, Antioxidant, Zoonotic, Tasmannia lanceolata, Tasmanian pepper.

\section{Correspondence:}

Dr. Mitchell Henry Wright

Department of Research and Development, First Choice College, Distribution Avenue, Molendinar-4214, Gold Coast, Queensland, AUSTRALIA.

Phone no: +61737357637

Email id: mitchell@fcc.edu.au

Dr. Ian Edwin Cock

${ }^{1}$ School of Environment and Science, Griffith University, Brisbane, Queensland, AUSTRALIA.

${ }^{3}$ Environmental Futures Research Institute, Griffith University, Brisbane-4111, Queensland, AUSTRALIA.

Phone no: +61737357637

Email id: I.Cock@griffith.edu.au

DOI: $10.5530 /$ pc.2019.4.30

\section{INTRODUCTION}

Tasmannia lanceolata (Poir.) A.C.Sm (Tasmanian pepper) is a shrub indigenous to the woodlands and cool temperate rainforests of Tasmania and the south-eastern coast of the mainland Australia, to the north of Sydney. ${ }^{1}$ It is a medium-large shrub of approximately $2-5 \mathrm{~m}$ in height. The berries leaves and bark of this plant are traditionally used medicinally. Australian Aborigines used T. lanceolata as a therapeutic agent to treat stomach disorders. ${ }^{1,2} T$. lanceolata has also been used traditionally for the treatment and cure of colic, venereal diseases, skin disorders and stomach aches. ${ }^{2}$ European colonists also documented the therapeutic properties of T. lanceolata and the bark was commonly used as a substitute for other herbal remedies and to treat scurvy (due to its high anti-antioxidant content.,3 Despite its extensive ethnobotanical usage, limited scientific studies into the therapeutic properties of T. lanceolata have been performed. It has been theorised that the plant's high antioxidant capacity may provide therapeutic benefits. Indeed, investigations of T. lanceolata within our laboratory have highlighted the inhibition of bacterial growth by $T$. lanceolata berries, leaves and peppercorns against panels of several distinct pathogenic and food spoilage bacteria $^{4-6}$ and protozoal parasites. ${ }^{7}$

The genus Yersinia (Y.) includes over than a dozen species of facultative anaerobes. ${ }^{8}$ Members of the genus are widespread in the environment but are also extensively present within animal populations. These bacteria are clinically important opportunistic pathogens and can cause human illness. The zoonotic aspect of these bacteria also poses a unique set of challenges in preventing infection, as they can persist in non-human hosts for an indefinite period until they encounter new hosts to infect. Diseases caused by Yersinia spp. vary in extremity and mortality, from the bubonic/pneumonic plagues (Yersinia pestis) to the yersiniosis (Yersinia enterocolitica). ${ }^{9,10}$

Yersinosis is an acute, bacterial gastroenteric infection and accounts for $>100,000$ illnesses annually in the United States. ${ }^{11}$ Characterized by abdominal aching, fever and/or diarrhoea, Y. enterocolitica infections frequently originate through the ingestion of infected food/ water. Indeed, almost $90 \%$ of all reported cases originate from this mode of infection. ${ }^{12}$ The prevention of yersiniosis is complicated by the fact that $Y$. enterocolitica can grow at $4^{\circ} \mathrm{C}$. Therefore, refrigeration alone does not afford adequate protection from contracting the illness. ${ }^{13}$ Although it is seldom life-threatening, the economic drain caused through temporary incapacitation from yersiniosis makes probing for effective treatment strategies particularly important. One tactic involves the utilization of natural resources such as plants that have been documented for their antibacterial capabilities. These relatively untapped reservoirs may impede Y. enterocolitica growth and thus may offer new management options for yersiniosis. Despite the documented ability of T. lanceolata to inhibit the growth of many bacterial species, to the best of our knowledge there have been no studies focusing on T. lanceolata against $Y$. enterocolitica growth. T. lanceolata berry and leaf extracts were prepared and their antibacterial potential was assessed against this pathogen. 


\section{MATERIALS AND METHODS}

\section{Plant collection and extraction}

Seedless, semi-dried T. lanceolata berries and dried leaf materials were acquired from Go Wild Harvest, Australia and stored at $-30^{\circ} \mathrm{C}$. Extracts were prepared as previously described. ${ }^{14-15}$ Briefly, plant materials were thawed and ground into a coarse powder. One-gram quantities of the ground plant materials were weighed into tubes in triplicate, followed by the addition of $50 \mathrm{~mL}$ of water, methanol, hexane, chloroform or ethyl acetate respectively. All solvents were obtained from Ajax Fine Chemicals, Australia (AR grade). The berry and leaf materials were extracted in each solvent for $24 \mathrm{hr}$ at $4^{\circ} \mathrm{C}$ with gentle shaking. The extracts were filtered through with filter paper (Whatman No. 54) under vacuum, followed by drying by rotary evaporation in an Eppendorf concentrator 5301. The dried extracts were weighed and resuspended in $10 \mathrm{~mL}$ deionised water (containing 1\% DMSO).

\section{Qualitative phytochemical studies}

Phytochemical analyses of the extracts for the presence of alkaloids, flavonoids, phenolic compounds, polysteroids, anthraquinones, cardiac glycosides, saponins, tannins and triterpenoids were conducted as previously described. ${ }^{16,17}$

\section{Antioxidant capacity}

The antioxidant capacity of each extract was assessed using the DPPH free radical scavenging method with modifications. ${ }^{18,19}$ Briefly, ascorbic acid references $(0-25 \mu \mathrm{g}$ per well) were prepared and the absorbances recorded at $515 \mathrm{~nm}$. All assays were completed alongside controls on each plate and all tests performed three times in triplicate $(n=9)$. The antioxidant capacity (based off of DPPH free radical scavenging ability) was calculated for each extract and expressed as $\mu \mathrm{g}$ ascorbic acid equivalents per gram of the original plant material extracted.

\section{Clinical Yersinia enterocolitica strain}

The clinical isolate strain of Yersinia enterocolitica used in this study was supplied by Ms. Jane Gifkins of the School of Natural Sciences Griffith University, Australia. Confirmation of bacterial identity was confirmed as previously described. ${ }^{20,21}$ All growth studies were performed using nutrient agar (Oxoid Ltd., Australia) under aerobic conditions. Incubations were at $30^{\circ} \mathrm{C}$ and the bacterium was subcultured and maintained in nutrient broth at $4^{\circ} \mathrm{C}$. Subculture purity was periodically confirmed as previously described. 22,23

\section{Evaluation of antimicrobial activity}

The antimicrobial activity of the T. lanceolata extracts were determined using a modified disc diffusion assay. ${ }^{24}$ Briefly, $100 \mu \mathrm{L}$ of $Y$. enterocolitica was grown in $10 \mathrm{~mL}$ of fresh nutrient broth until they reached a count of $\sim 10^{8}$ cells $/ \mathrm{mL}$. Aliquots $(100 \mu \mathrm{L})$ of the bacterial suspensions were spread onto plates and each extract was tested for antibacterial activity using $6 \mathrm{~mm}$ sterilised filter paper discs. Discs were infused with $10 \mu \mathrm{L}$ of T. ferdinandiana extracts, allowed to dry and placed onto the inoculated plates. The plates were allowed to stand at $4^{\circ} \mathrm{C}$ for $2 \mathrm{~h}$ before incubation at $30^{\circ} \mathrm{C}$ for $24 \mathrm{hr}$. The diameters of the inhibition zones were measured to the closest whole millimetre. Each assay was performed three times, with internal triplicates $(n=9)$. Mean values $( \pm$ SEM) are reported in this study. Standard discs of chloramphenicol $(2 \mu \mathrm{g})$ were prepared and used as positive controls to compare antibacterial activity. Filter discs infused with $10 \mu \mathrm{L}$ of distilled water were used as a negative control.

\section{Minimum inhibitory concentration (MIC) determination}

The Minimum Inhibitory Concentrations (MIC) of the extracts was determined as previously described. ${ }^{25}$ Briefly, the plant extracts were diluted in deionised water and tested across a range of concentrations. Discs were infused with $10 \mu \mathrm{L}$ of the extract dilutions, allowed to dry and placed onto inoculated plates. The assay was performed as outlined above and graphs of the zone of inhibition versus concentration were plotted. Linear regression was used to determine MIC values.

\section{Toxicity screening}

\section{Reference toxin for toxicity screening}

Potassium dichromate $\left(\mathrm{K}_{2} \mathrm{Cr}_{2} \mathrm{O}_{7}\right)$ (AR grade, Chem-Supply, Australia) was prepared using $0.22 \mu \mathrm{M}$ filter-sterilised, distilled water $(4 \mathrm{mg} / \mathrm{mL})$ and serially diluted in synthesised, artificial seawater for use in the Artemia franciscana nauplii bioassay.

\section{Artemia franciscana nauplii toxicity screening}

Toxicity was tested using an adapted Artemia franciscana nauplii mortality assay. ${ }^{26}$ Briefly, $400 \mu \mathrm{L}$ of seawater containing 43 (mean 43.2, $n=155$, SD 14.5) A. franciscana nauplii were added to wells of a 48 well plate and immediately used in the bioassay. Volumes of $400 \mu \mathrm{L}$ of reference toxin or the diluted plant extracts were transferred to the wells and incubated at $25 \pm 1^{\circ} \mathrm{C}$ under artificial light (1000 Lux). A $400 \mu \mathrm{L}$ volume of seawater was used as a negative control and was run in triplicate for each plate. All treatments were performed three times, each with internal triplicates $(n=9)$. The wells were checked at regular intervals and the deceased nauplii were counted. Nauplii death was determined if no appendage movement was observed within a $10 \mathrm{sec}$ interval (or any period thereafter). After $24 \mathrm{hr}$, all nauplii were sacrificed and counted to determine the total \% mortality per well. The $\mathrm{LC}_{50}$ with $95 \%$ confidence limits for each treatment was calculated using probit analysis.

\section{Statistical analysis}

Data is expressed as the mean \pm SEM of three independent experiments, each with technical triplicates $(n=9)$.

\section{RESULTS}

Extraction of $1 \mathrm{~g}$ of the T. lanceolata plant materials with the solvents yielded dried plant extracts ranging from $9 \mathrm{mg}$ ( $T$. lanceolata leaf hexane extract) to $144 \mathrm{mg}$ (methanolic T. lanceolata leaf extract; Table 1). Aqueous and methanolic extracts generally gave relatively high yields of dried extracted material compared to the other extracts. The dried extracts were resuspended in $10 \mathrm{~mL}$ of deionised water (containing $1 \% \mathrm{DMSO}$ ), resulting in the extract concentrations shown in Table 1.

Qualitative phytochemical studies showed little difference between the aqueous and methanolic extracts. However, there were notable differences between these and the ethyl acetate extracts. High levels of phenolics (both water soluble and insoluble) were extracted in the aqueous and methanolic samples. There were substantially lower levels detected in the corresponding ethyl acetate extracts. Similarly, there was a lower level of flavonoids detected in the ethyl acetate extracts than the corresponding aqueous and methanolic extracts. Triterpenes were detected in both methanolic and ethyl acetate extracts, although they were absent in the aqueous extracts.

To assess the inhibitory activity of the crude T. lanceolata plant extracts against $Y$. enterocolitica, $10 \mu \mathrm{L}$ aliquots of each were screened with a disc diffusion assay. Antibacterial activity against $Y$. enterocolitica was observed in all 10 extracts tested (Figure 1). The methanolic berry extract was the most potent inhibitor of growth, with inhibition zones of $11.3 \pm 0.3 \mathrm{~mm}$. Similarly, strong inhibitory zones were observed in ethyl 


\begin{tabular}{|c|c|c|c|c|c|c|c|c|c|c|c|c|c|c|c|}
\hline 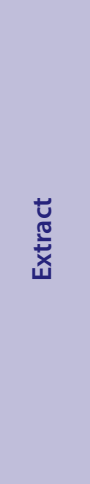 & 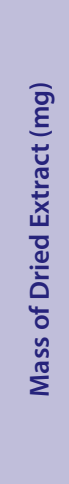 & 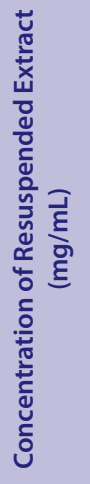 & 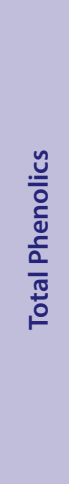 & 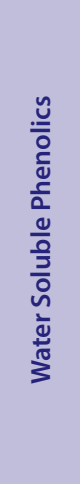 & 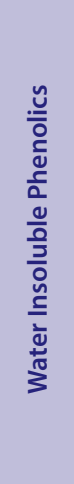 & 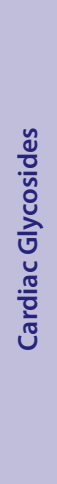 & 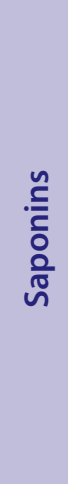 & 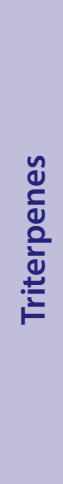 & $\begin{array}{l}\frac{n}{0} \\
\frac{0}{0} \\
\frac{\pi}{n} \\
\frac{\pi}{0} \\
0\end{array}$ & 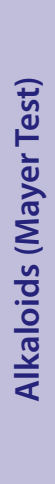 & 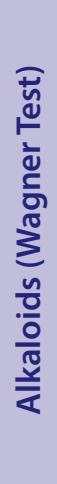 & $\begin{array}{l}\frac{n}{0} \\
\frac{0}{0} \\
\frac{1}{0} \\
\frac{\pi}{4}\end{array}$ & 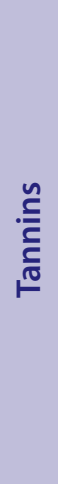 & 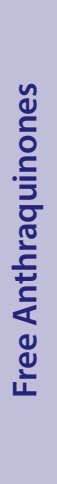 & 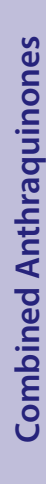 \\
\hline TLLW & 134 & 13.4 & +++ & +++ & +++ & - & ++ & - & - & - & - & +++ & - & - & - \\
\hline TLLM & 144 & 14.4 & +++ & +++ & +++ & - & +++ & + & - & - & - & +++ & - & - & - \\
\hline TLLC & 37 & 3.7 & + & - & + & - & - & - & - & - & - & - & - & - & - \\
\hline TLLH & 9 & 0.9 & - & - & - & - & - & - & - & - & - & - & - & - & - \\
\hline TLLE & 17 & 1.7 & + & + & ++ & - & - & + & - & - & - & ++ & - & - & - \\
\hline TLBW & 111 & 11.1 & +++ & +++ & +++ & - & - & - & - & - & - & +++ & - & - & - \\
\hline TLBM & 171 & 17.1 & +++ & +++ & +++ & - & ++ & + & - & - & - & +++ & - & - & - \\
\hline TLBC & 47.2 & 4.7 & + & + & + & - & - & - & - & - & - & - & - & - & - \\
\hline TLBH & 11 & 1.1 & - & - & - & - & - & - & - & - & - & - & - & - & - \\
\hline TLBE & 56.7 & 5.7 & + & + & ++ & - & + & ++ & - & - & - & ++ & - & - & - \\
\hline
\end{tabular}

+++ indicates a large response; ++ indicates a moderate response; + indicates a minor response; - indicates no response in the assay. TLLW = aqueous T. lanceolata leaf extract; TLLM = methanolic $T$. lanceolata leaf extract TLBC $=$ chloroform $T$. lanceolata leaf extract; TLBH $=T$. lanceolata leaf extract TLLE $=$ ethyl acetate $T$. lanceolata leaf extract; TLBW $=$ aqueous $T$. lanceolat $a$ berry extract; TLBM $=$ methanolic $T$. lanceolata berry extract; TLBC $=$ chloroform $T$. lanceolata berry extract; TLBH $=$ T. lanceolata berry extract; TLBE = ethyl acetate $T$. lanceolata berry extract.

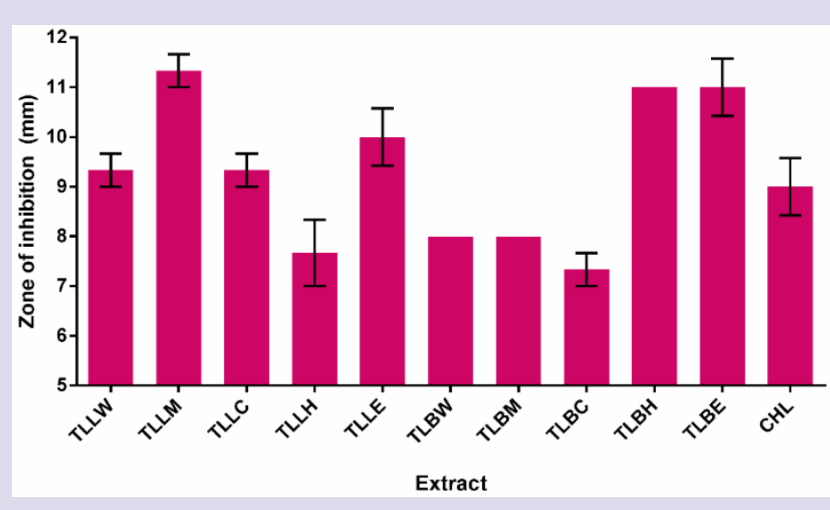

Figure 1: Growth inhibitory activity of T. lanceolata leaf and berry extracts against the $Y$. enterocolitica clinical isolate measured as zones of inhibition ( $\mathrm{mm}$ ). TLLW = aqueous $T$. lanceolata leaf extract; TLLM = methanolic T. lanceolata leaf extract; TLBC = chloroform T. lanceolata leaf extract; $T L B H=T$. lanceolata leaf extract TLLE $=$ ethyl acetate $T$. lanceolata leaf extract; TLBW = aqueous $T$. lanceolata berry extract; TLBM = methanolic $T$. lanceolata berry extract; $T L B C=$ chloroform $T$. lanceolata berry extract; $T L B H=T$. lanceolata berry extract; $\mathrm{TLBE}=$ ethyl acetate $\mathrm{T}$. lanceolata berry extract; $\mathrm{CHL}=$ Chloramphenicol $(2 \mu \mathrm{g})$. Results are expressed as mean zones of inhibition \pm SEM. acetate leaf extract $(10.0 \pm 0.6 \mathrm{~mm})$ as well as the hexane $(11.0 \pm 0.0 \mathrm{~mm})$ and ethyl acetate $(11.0 \pm 0.6 \mathrm{~mm})$ berry extracts. The chloramphenicol control had inhibitory zones of $9.0 \pm 0.6 \mathrm{~mm}$ which is notably less than several of the T. lanceolata extracts.

The antimicrobial efficacy was further quantified by determining the MIC values (Table 2). All the extracts were determined to be potent inhibitors of $Y$. enterocolitica growth, with MIC $<1000 \mu \mathrm{g} / \mathrm{mL}$ for all extracts except the chloroform berry extract. The $T$. lanceolata leaf extracts were generally more potent $Y$. enterocolitica growth inhibitors than the corresponding berry extracts. Indeed, a MIC of $30 \mu \mathrm{g} / \mathrm{mL}$ was determined for the ethyl acetate T. lanceolata leaf extract.

All extracts were initially screened at $2000 \mu \mathrm{g} / \mathrm{mL}$ in the Artemia nauplii assay as a measure of toxicity (Figure 2). For comparison, the reference toxin potassium dichromate $(1000 \mu \mathrm{g} / \mathrm{mL})$ was also tested in the bioassay. The potassium dichromate reference toxin was rapid in its onset, promoting nauplii death within the first $3 \mathrm{hr}$ of exposure, with 100 $\%$ mortality evident following $4-5 \mathrm{hr}$ (unpublished results). Similarly, all the T. lanceolata extracts displayed significant mortality rates following $24 \mathrm{hr}$ exposure (>50\%).

\section{DISCUSSION}

Despite the initial efficacy of clinically used antibiotics, recent increases in bacterial resistance have made the development of new antibiotic 
Table 2: Minimum inhibitory concentration $(\mu \mathrm{g} / \mathrm{mL})$ of the plant extracts and $\mathrm{LC}_{50}$ values $(\mu \mathrm{g} / \mathrm{mL})$ in the Artemia nauplii bioassay.

\begin{tabular}{ccc}
\hline Extract / Control & MIC & LC \\
\hline TLLW & 370 & 2665 \\
TLLM & 318 & 2096 \\
TLLC & 53 & 2540 \\
TLLH & 900 & 3058 \\
TLLE & 30 & 2766 \\
TLBW & 600 & 2376 \\
TLBM & 425 & 2573 \\
TLBC & 4700 & 1846 \\
TLBH & 34 & 2875 \\
TLBE & 276 & 3132 \\
PD & - & 186 \\
SW & - & - \\
\hline
\end{tabular}

Numbers indicate the mean $\mathrm{MIC}$ and $\mathrm{LC}_{50}$ values of triplicate determinations. indicates no inhibition.

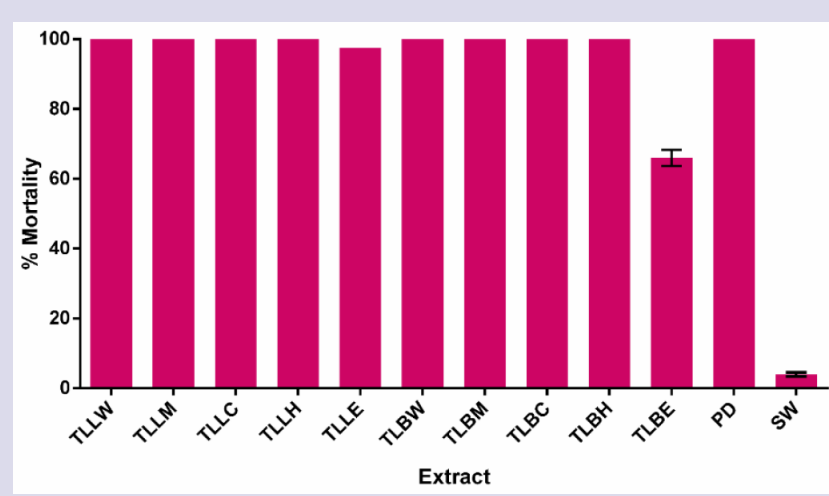

Figure 2: The lethality of the T. lanceolata extracts $(2000 \mu \mathrm{g} / \mathrm{mL})$ and the potassium dichromate control $(1000 \mu \mathrm{g} / \mathrm{mL})$ towards Artemia franciscana nauplii after $24 \mathrm{hr}$ exposure. TLLW = aqueous $T$. lanceolata leaf extract; TLLM = methanolic $T$. lanceolata leaf extract; TLBC = chloroform $T$. lanceolata leaf extract; $T L B H=T$. lanceolata leaf extract TLLE = ethyl acetate $T$. lanceolata leaf extract; TLBW = aqueous $T$. lanceolata berry extract; TLBM = methanolic $T$. lanceolata berry extract; $\mathrm{TLBC}=$ chloroform $\mathrm{T}$. lanceolata berry extract; TLBH = $T$. lanceolata berry extract; TLBE = ethyl acetate $T$. lanceolata berry extract; $\mathrm{PD}=$ potassium dichromate control; $\mathrm{SW}=$ artificial seawater control. Results are expressed as mean $\%$ mortality \pm SEM.

therapies a high priority. ${ }^{27}$ A parallel decrease in the introduction of new antibiotic therapies in recent years has further compounded this problem. As a result, interest in re-evaluating medicinal plants for new antibiotic chemotherapies has escalated substantially in recent years. ${ }^{28}$ Our study was undertaken to investigate the potential of the endemic Australian plant T. lanceolata to inhibit the growth of Y. enterocolitica, thereby blocking yersiniosis and treating it once it is established. T. lanceolata was selected for this study as it has a history of therapeutic usage to treat microbial infections, ${ }^{1}$ and numerous recent investigations have reported on its antibacterial properties against a broad panel of bacterial pathogens, including several bacteria associated with diarrhoea and dysentery. ${ }^{4,6,7}$ T. lanceolata extracts have also recently been reported to inhibit the proliferation of the gastrointestinal protozoan parasite
Giardia duodenalis, ${ }^{7}$ indicating its therapeutic potential against both prokaryotic and eukaryotic pathogens. However, despite the relative wealth of information into the therapeutic potential of T. lanceolata, it is yet to be comprehensively studied for antibacterial activity against many bacterial species associated with food poisoning. Here we report growth inhibitory activity for T. lanceolata berry and leaf extracts against the bacterial cause of the gastrointestinal disease yersiniosis; an acute infection acquired through the ingestion of food (particularly pork) ${ }^{12}$ contaminated with Y. enterocolitica.

Potent $Y$. enterocolitica growth inhibitory activity was evident in the T. lanceolata fruit and leaf extracts. Indeed, with the exception of the chloroform berry extract, MIC values of substantially $<1000 \mu \mathrm{g} / \mathrm{mL}$ were calculated for all extracts. The ethyl acetate and chloroform leaf extracts (MICs of 30 and $53 \mu \mathrm{g} / \mathrm{mL}$ respectively) and the hexane berry extract $(\mathrm{MIC}=34 \mu \mathrm{g} / \mathrm{mL})$ were particularly potent growth inhibitors. The berry and leaf methanolic and water extracts, as well as the ethyl acetate leaf extract, also exhibited strong growth inhibitory activity against Y. enterocolitica; albeit with higher MIC values $(250-300 \mu \mathrm{g} / \mathrm{mL})$. Therefore, these extracts show good potential in the prevention and treatment of yersiniosis and are potential targets for future drug discovery. Furthermore, given that T. lanceolata berries and leaves are edible herbs and spices, their addition to foods would not only provide pleasant flavour enhancements, but could also inhibit food spoilage and the chances of contracting food poisoning (including yersiniosis).

Detailed analyses into the phytochemistry of the T. lanceolata fruit and leaf extracts was beyond the scope of this study. However, several notable compounds have been previously been reported in T. lanceolata extracts and essential oils. ${ }^{1}$ These include multiple monoterpenoids (e.g. 1, 8 -cineole, terpinen-4-ol, $\alpha$-pinene and $\beta$-pinene) and sesquiterpenoids (particularly polygodial), flavonoids (including quercetin and rutin), other phenolics (including coumaric acid and caffeic acid) and hydrocarbons. Many of these compounds have also been isolated from other plant species and have been shown to have potent antimicrobial activity. ${ }^{1}$ Therefore, these components may also contribute to the Y. enterocolitica growth inhibitory properties of the extracts tested in this study. Of particular note, relatively high abundances of the sesquiterpenoid polygodial have been reported in T. lanceolata berry and leaf extracts, with higher relative levels detected in the berry extracts. Indeed, polygodial can account for approximately $40 \%$ of commercial $T$. lanceolata essential oil components. ${ }^{1,29}$ Interestingly, several studies have reported the therapeutic properties of this compound, including its antibacterial, ${ }^{29}$ antifungal, ${ }^{30}$ anti-hyperalgesia, ${ }^{31}$ anti-inflammatory, antiallergic and vasorelaxation activities. ${ }^{32}$ Other structurally similar sesquiterpenoids have also been reported in similar T. lanceolata extracts. ${ }^{7}$ Of particular interest, salidroside was present in all inhibitory T. lanceolata berry extracts. Salidroside has been linked with antibacterial and anti-parasitic activity in multiple plants. Plants of the genus Warburgia are known to have significant levels of salidroside ${ }^{33}$ and several Warburgia spp. have been reported to have strong antimicrobial and antiparasitic activities. ${ }^{34,35}$

T. lanceolata berry and leaf extracts have also been reported to contain an abundance of gallotannin components. ${ }^{7}$ Gallotannins have been reported to inhibit the growth of a broad spectrum of microbial species ${ }^{36}$ via binding cell surface lipoteichoic acid and proline-rich cell surface proteins, ${ }^{37,38}$ and by inhibiting glucosyltransferase enzymes. ${ }^{39}$ The stilbene combretastatin A1 was also putatively identified in all T. lanceolata berry extracts, ${ }^{7}$ although the relatively low peak size indicates that it is present in low abundance. Combretastatin's are well known for their potent ability to block cancer cell progression and induce apoptosis by binding intracellular tubulin, thereby disrupting microtubule formation. ${ }^{40}$ Combretastatin's act in a similar fashion to that of colchicine $(\mathrm{N}-[(7 \mathrm{~S})$ 1,2,3,10-tetramethoxy-9-oxo-5,6,7,9-tetrahydrobenzo[a]heptlen-7-yl] 
acetamide) by binding the colchicine's binding site in tubulin. ${ }^{41}$ Thus, the T. lanceolata combretastatin's may block bacterial replication events.

The findings reported here also indicate that the T. lanceolata berry and leaf extracts were nontoxic, with $\mathrm{LC}_{50}$ values substantially $>2000 \mu \mathrm{g} / \mathrm{mL}$. Toxicity was assessed in this study using the test organism $A$. franciscana. The lack of toxicity of the T. lanceolata extracts in our study indicates that the extracts are safe for medicinal usage. This is hardly surprising as T. lanceolata is highly nutritious and has long been used as a spice (berries) and herb (leaves). However, whilst the extracts examined in this report have potential as $Y$. enterocolitica growth inhibitory agents, caution is needed before these compounds can be applied to medicinal purposes. Toxicity towards $A$. franciscana has previously been shown to correlate well with toxicity towards human cells for many toxins. ${ }^{7}$ However, further studies are required to determine whether this is also true for the T. lanceolata extracts examined in these studies. The results of this study indicate that the T. lanceolata extracts warrant further study due to their $Y$. enterocolitica growth inhibitory activity. Purification and identification of the bioactive components is needed to examine the mechanisms of action of these agents.

\section{CONCLUSION}

The results of this study demonstrate the potential of T. lanceolata berry and leaf extracts to inhibit $Y$. enterocolitica growth. The mid-low polarity ethyl acetate, chloroform and hexane T. lanceolata extracts were particularly potent growth inhibitors, with MIC values $<100 \mu \mathrm{g} / \mathrm{mL}$ quantified. However, before being deemed acceptable for therapeutic uses, further cell line toxicity studies are required to verify the safety of these extracts. Furthermore, studies aimed at the purification and identification of the bioactive components are required to examine the mechanisms of action of these extracts.

\section{ACKNOWLEDGEMENT}

Financial support for this work was provided by the Environmental Futures Research Institute and the School of Environment and Science, Griffith University, Australia. The authors are most grateful to Jane Gifkins for providing the Y. enterocolitica strain used in these studies.

\section{CONFLICT OF INTEREST}

The authors have no conflicts of interest.

\section{ABBREVIATIONS}

DMSO: Dimethyl sulfoxide; $\mathbf{L C}_{50}$ : The concentration required to achieve 50\% mortality; MIC: minimum inhibitory concentration.

\section{REFERENCES}

1. Cock IE. The phytochemistry and chemotherapeutic potential of Tasmannia lanceolata (Tasmanian pepper): A review. Pharmacog Commn. 2013;3(4):13-25.

2. Cock IE. Medicinal and aromatic plants - Australia. In Ethnopharmacology section, Biological, Physiological and Health Sciences. Encyclopedia of Life Support Systems (EOLSS), Developed under the auspices of UNESCO, EOLSS Publishers, Oxford, UK. 2011;1(2):50-2. (http://www.eolss.net).

3. Netzel M, Netzel G, Tian $Q$, et al. Native Australian fruits-a novel source of antioxidants for food. Innov Food Sci Emerg Technol. 2007;8(3):339-46. DOI: 10.1016/j.ifset.2007.03.007

4. Cock IE, Sirdaarta J, Winnett V, et al. Phytochemical analysis of Tasmannia lanceolata extracts that inhibit the microbial triggers of rheumatoid arthritis. South Afr J Bot. 2015;98:174. DOI: 10.1016/j.sajb.2015.03.029

5. Winnett $\mathrm{V}$, Sirdaarta J, White A, et al. Inhibition of Klebsiella pneumoniae growth by selected Australian plants: Natural approaches for the prevention and management of ankylosing spondylitis. Inflammopharmacol. 2017;25(2):223-5. DOI: 10.1007/s10787-017-0328-1

6. Wright MH, Lee CJ, Arnold MSJ, et al. GC-MS analysis of Tasmannia lanceolata extracts which inhibit the growth of the pathogenic bacterium Clostridium perfringens. Pharmacog J. 2017;9(5):626-37. DOI: 10.5530/pj.2017.5.100
7. Rayan P, Matthews B, McDonnell P, et al. Phytochemical analysis of Tasmannia lanceolata extracts and inhibition of Giardia duodenalis proliferation. Pharmacogn J. 2016;8(3):291-9. DOI: 10.5530/pj.2016.3.19

8. Tan SY, Dutta A, Jakubovics NS, et al. Yersinia Base: A genomic resource and analysis platform for comparative analysis of Yersinia. BMC Bioinformatics. 2015;16(9):1-13. DOI: 10.1186/s12859-014-0422-y

9. Wright $\mathrm{MH}$, Arnold MSJ, Aldosary $\mathrm{H}$, et al. Bioactive constituents of Terminalia ferdinandiana Exell: A pharmacognistic approach towards the prevention and treatment of yersiniosis. Pharmacog Commn. 2016;6(3):152-63. DOI: 10.5530/ pc. 2016.3 .5

10. Wright $\mathrm{MH}$, Greene AC, Cock IE. Investigating the pharmacognostic potential of Indian Terminalia Spp. in the treatment and prevention of yersiniosis. Pharmacog Commn. 2017;7(3):108-13. DOI: 10.5530/pc.2017.3.16

11. Ong KL, Gould LH, Chen DL. Changing epidemiology of Yersinia enterocolitica infections: Markedly decreased rates in young black children, Foodborne Diseases Active Surveillance Network (Food Net), 1996-2009. Clin Infect Dis. 2012;54(S5):S385-90. DOI: 10.1093/cid/cis053

12. Bhaduri S, Wesley IV, Bush EJ. Prevalence of pathogenic Yersinia enterocolitica strains in pigs in the United States. Appl Environ Microbiol. 2005;71(11):7117-21.

13. Jiang GC, Kang DH, Fung DY. Enrichment procedures and plating media for isolation of Yersinia enterocolitica. J Food Prot. 2000;63(11):1483-6.

14. Wright MH, Sirdaarta J, Matthews B, et al. Growth inhibitory activity of Kakadu plum extracts against the opportunistic pathogen Clostridium perfringens: New leads in the prevention and treatment of Clostridial myonecrosis. Pharmacog Commn. 2016;8(2):144-53. DOI: 10.5530/pc.2016.2.7

15. McManus $\mathrm{K}$, Wood A, Wright $\mathrm{MH}$, et al. Terminalia ferdinandiana Exell. extracts inhibit the growth of body odour-forming bacteria. Int J Cosmetic Sci. 2017;39(5):500-10. DOI: 10.1111/ics.12403

16. Lee CJ, Wright MH, Arnold MSJ, et al. Inhibition of Streptococcus pyogenes growth by native Australian plants: New approaches towards the management of impetigo, pharyngitis and rheumatic heart disease. Pharmacogn Commn. 2016;6(3):164-73

17. Wright $\mathrm{MH}$, Arnold MSJ, Lee $\mathrm{CJ}$, et al. Qualitative phytochemical analysis and antibacterial activity evaluation of Indian Terminalia spp. against the pharyngitis causing pathogen Streptococcus pyogenes. Pharmacog Commn. 2016;6(2):85-92. DOI: $10.5530 / p c .2016 .2 .6$

18. Jamieson N, Sirdaarta J, Cock IE. The anti-proliferative properties of Australian plants with high antioxidant capacities against cancer cell lines. Pharmacog Commn. 2014;4(4):71-82. DOI: 10.5530/pc.2014.4.8

19. Shalom J, Cock IE. Terminalia ferdinandiana Exell. fruit and leaf extracts inhibit proliferation and induce apoptosis in selected human cancer cell lines. Nutrition and Cancer. 2018;70(4):579-93. DOI: 10.1080/01635581.2018.1460680

20. Wright MH, Adelskov J, Greene AC. Bacterial DNA extraction using individual enzymes and phenol/chloroform separation. J Microbiol Biol Educ. 2017:18(2):18.2.48. DOI: 10.1128/jmbe.v18i2.1348

21. Wright $\mathrm{MH}$, Geszvain K, Oldham VE, et al. Oxidative formation and removal of complexed Mn (III) by Pseudomonas Species. Front Microbiol. 2018;9(560):1-11. DOI: $10.3389 / \mathrm{fmicb} .2018 .00560$

22. Wright $M H$, Farooqui SM, White $A R$, et al. Production of manganese oxide nanoparticles by Shewanella species. Appl Environ Microbiol. 2017;82(17):5402-9. DOI: 10.1128/AEM.00663-16

23. Wright MH, Hanna JG, Pica DA, et al. Pseudomonas laurentiana sp. nov., an $\mathrm{Mn}$ (III)-oxidizing bacterium isolated from the St. Lawrence Estuary. Pharmacog Commn. 2018;8(4):153-7. DOI: 10.5530/pc.2018.4.32

24. Wright MH, Sirdaarta J, White A, et al. GC-MS headspace analysis of Terminalia ferdinandiana fruit and leaf extracts which inhibit Bacillus anthracis growth. Pharmacog J. 2017;9(1):73-82. DOI: 10.5530/pj.2017.1.14

25. Wright $\mathrm{MH}$, Greene AC, Cock IE. Inhibition of Bacillus anthracis growth by Australian native plants used traditionally as antibacterial medicines. Pharmacog Commn. 2015;7(6):389-96. DOI: 10.5530/pj.2015.6.13

26. Wright MH, Matthews B, Arnold MSJ, et al. The prevention of fish spoilage by high antioxidant Australian culinary plants: Shewanella putrefaciens growth inhibition. Int J Food Sci Technol. 2016;51(3):801-13. DOI: 10.1111/ijfs.13026

27. Cheesman MJ, Ilanko A, Blonk B, et al. Developing new antimicrobial therapies: Are synergistic combinations of plant extracts/compounds with conventional antibiotics the solution?. Pharmacog Rev. 2017;11(22):57-72. DOI: 10.4103/ phrev.phrev_21_17

28. Aiyegoro OA, Okoh Al. Use of bioactive plant products in combination with standard antibiotics: Implications in antimicrobial chemotherapy. J Med Plants Res. 2009;3(13):1147-52.

29. Kubo I, Fujita K, Lee SH, et al. Antibacterial activity of polygodial. Phytother Res 2005;19(12):1013-7. DOI: 10.1002/ptr.1777

30. DeAlmeida ATM, Ribeiro FL, Kloos H, et al. Polygodial, the fungitoxic component from the Brazilian medicinal plant Polygonum punctatum. Mem Inst Owwaldo Cruz. 2001;96(6):831-3. DOI: 10.1590/s0074-02762001000600016

31. Mendes GL, Santos ARS, Campos MM, et al. Anti-hyperalgesic properties of the extract and of the main sesquiterpene polygodial isolated from the barks of Drymis winteri (Winteraceae). Life Sci. 1998:63(5):369-81. DOI: 10.1016/s00243205(98)00285-9 
32. DaCunha FM, Frode TS, Mendes GL, et al. Additional evidence for the antiinflammatory and anti-allergic properties of the sesquiterpene polygodial. Life Sci. 2001;70(2):159-69. DOI: 10.1016/s0024-3205(01)01387-x

33. Maroyi A. The genus Warburgia: A review of its traditional uses and pharmacology. Pharmaceut Biol. 2014;52(3):378-91. DOI: 10.3109/13880209.2013.837935

34. Ngure PK, Tonui WK, Ingonga J, et al. In vitro antileishmanial activity of extracts of Warburgia ugandensis (Canellaceae), a Kenyan medicinal plant. J Med Plant Res. 2009;3(2):61-6.

35. Ahmed M, Laing MD, Nsahlai IV. In vitro anthelmintic activity of crude extracts of selected medicinal plants against Haemonchus contortus from sheep. J Helminthol. 2013;87(2):174-9. DOI: 10.1017/S0022149X1200020X

36. Buzzini $P$, Arapitsas $P$, Goretti $M$, et al. Antimicrobial activity of hydrolysable tannins. Mini-Rev Med Chem. 2008;8(12):1179-87.
37. Wolinsky LE, Sote EO. Isolation of natural plaque-inhibiting substances from 'Nigerian chewing sticks'. Caries Res. 1984;18(3):216-25. DOI: 10.1159/000260768

38. Hogg SD, Embery G. Blood-group-reactive glycoprotein from human saliva interacts with lipoteichoic acid on the surface of Streptococcus sanguis cells. Arch Oral Biol. 1982;27(3):261-8. DOI: 10.1016/0003-9969(82)90060-7

39. Wu-Yuan CD, Chen CY, Wu RT. Gallotannins inhibit growth, water-soluble glucan synthesis and aggregation of Streptococci mutans. J Dental Res. 1988;67(1):51-5. DOI: $10.1177 / 00220345880670011001$

40. Dark GG, Hill SA, Prise VE, et al. Combretastatin A-4, an agent that displays potent and selective toxicity towards tumor vasculature. Cancer Res. 1997;57(10):1829-34

41. Bhardwaj S, Bakshi S, Chopra B, et al. Synthesis of combretastatin analogues with their potent anticancer activity. Int J Res Pharm Sci. 2010;1(4):s414-6.

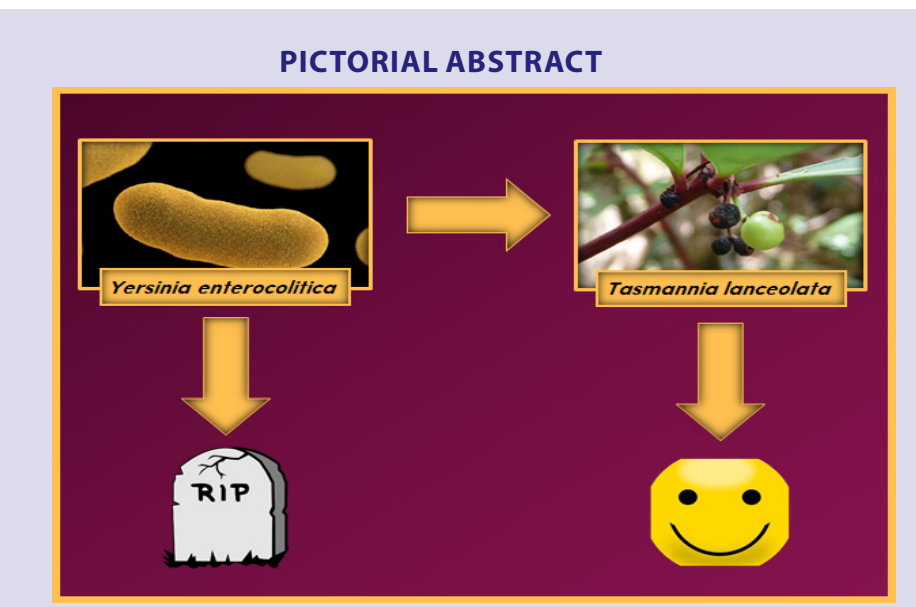

\section{SUMMARY}

- T. lanceolata berry and leaf extracts were screen for growth inhibitory activity against $Y$. entercolitica.

- Most extracts were potent inhibitors of Y. entercolitica growth

- The leaf extracts were generally more potent than the corresponding berry extracts.

- The leaf ethyl acetate and chloroform (30 and $53 \mathrm{ug} / \mathrm{mL}$ respectively) and the berry hexane extract $(34 \mathrm{ug} / \mathrm{mL})$ were particularly potent.

- All extracts were nontoxic in the Artemia nauplii assay.

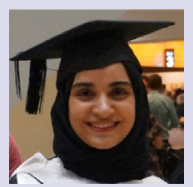

\section{ABOUT AUTHORS}

Ms. Huda Aldosary is undertaking her Ph.D at Griffith University (Brisbane, Australia) under the supervision of Dr. Anthony Greene. Her primarily interests involve the investigation of bacterial hydrocarbon degradation and the potential for these processes in the remediation of contaminated sites. She has extensive experience with anaerobic organisms and specialises in extremophiles.

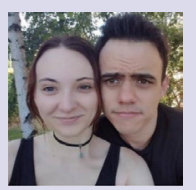

Dr. Mitchell Henry Wright is a Geomicrobiologist who received his Ph.D in 2014 for his work investigating the manganese reduction/oxidation characteristics of environmental bacteria. From 2016 to 2018 he undertook a postdoctoral researcher role under the mentorship of Prof. Bradley Tebo, where he explored the bacterial oxidative formation and removal of complexed Mn (III) and the implications of these processes on the global ocean. Upon returning to Australia, Dr. Mitchell H. Wright was recruited by First Choice College and to date, oversees their Department of Research and Development. Additionally, he has returned to his former lab (lead by Dr. Ian Cock) to continue his research into the antimicrobial potential of native plants.

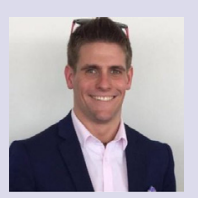

Mr. Cameron Lee completed his Bachelor of Science (BSc) in 2015 and is currently undertaking his PhD with Dr. Anthony Carlson Greene. His research involves the investigation of thermophilic anaerobes that utilize toxic metals in anaerobic respiration (including uranium and arsenic). He has extensive experience in anaerobic cultivation/isolation and in numerous analytical techniques associated with heavy metal analysis.

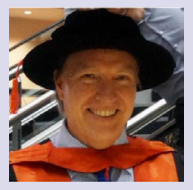

Dr. Anthony Carlson Greene is a senior lecturer and researcher at Griffith University, Brisbane Australia. He obtained his Ph.D in Microbiology from the University of New South Wales and focuses on extreme environments, Bioremediation and Geomicrobiology. His specific interests include the microbial ecology of thermophilic, saline and alkaliphilic environments and the mechanisms and industrial potential of extremophilic bacteria contained therein.

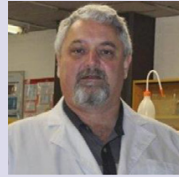

Dr. Ian Cock leads a research team in the Environmental Futures Research Institute and the School of Natural Sciences at Griffith University, Australia. His research involves bioactivity and phytochemical studies into a variety of plant species of both Australian and international origin, including Aloe vera, South Asian and South American tropical fruits, as well as Australia plants including Scaevola spinescens, Pittosporum phylliraeoides, Terminalia ferdinandiana (Kakadu plum), Australian Acacias, Syzygiums, Petalostigmas and Xanthorrhoea johnsonii (grass trees). This range of projects has resulted in over 100 publications across a variety of peer reviewed journals. 